\title{
Inhibitory processes in auditory selective attention: Evidence of location-based and frequency-based inhibition of return
}

\author{
TODD A. MONDOR \\ Mount Allison University, Sackville, New Brunswick, Canada \\ LYNN M. BREAU \\ Dalhousie University, Halifax, Nova Scotia, Canada \\ and \\ BRUCE MILLJKEN \\ McMaster University, Hamilton, Ontario, Canada
}

\begin{abstract}
The possibility that there is an inhibitory component to auditory covert orienting was addressed. Each trial consisted of a cue followed by a target, and listeners were required to detect, localize, or identify the frequency of the target. At 150-msec stimulus onset asynchrony (SOA), performance was best when stimuli sounded from the same location or were of the same frequency. However, at 750-msec SOA, performance was best when stimuli differed in location or were of different frequencies. These results document the existence of both location-based and frequency-based auditory inhibition of return.
\end{abstract}

Inhibition of return (IOR) is defined as a delay in returning attention to a previously attended location (e.g., Posner \& Cohen, 1984). In experiments that reveal IOR, participants are presented, on each trial, with a cue followed by a target about which they are required to make a detection or identification judgment. The time between the onset of the cue and the onset of the target (stimulus onset asynchrony, SOA) is varied. There is typically no predictive relation between the cue and target because the two are equally likely to be the same or different on one feature but identical in all other respects. At short SOAs of less than $300 \mathrm{msec}$, participants usually respond more quickly to the target when it is identical to the cue in the feature of interest (repeat trials). In contrast, at longer SOAs, target judgments are faster when the cue and target differ in the feature of interest (change trials; e.g., Maylor \& Hockey, 1985; Posner \& Cohen, 1984; Rafal, Calabresi, Brennan, \& Sciolto, 1989). It has been argued that IOR occurs whether target detection (e.g.,

This paper is dedicated to the memory of M. Philip Bryden. The research was supported by grants from the Natural Sciences and Engineering Research Council of Canada (NSERC) and the Heart and Stroke Foundation of New Brunswick to T.A.M., by a Bell Research Fellowship from Mount Allison University to L.M.B., and by an NSERC grant to B.M. Some of the research on which this paper is based was presented at the annual meeting of the Canadian Society for Brain, Behaviour and Cognitive Science, Halifax, June 1995. We would like to thank Lester Krueger, Arthur Samuel, and two anonymous reviewers for their insightful comments. Correspondence should be addressed to T. A. Mondor at the Department of Psychology, Mount Allison University, Sackville, New Brunswick, Canada E0A 3C0 (e-mail: tmondor@mta.ca).
Huey \& Wexler, 1994; Kwak \& Egeth, 1992; Tipper, Driver, \& Weaver, 1991) or identification of target form (e.g., Pratt, 1995; Tipper, Weaver, Jerreat, \& Burak, 1994), color (e.g., Law, Pratt, \& Abrams, 1995), or location (e.g., Gibson \& Egeth, 1994b) is required, and even when the temporal order of two targets must be judged (Gibson \& Egeth, 1994a). Thus, visual IOR appears to be a robust, reliable phenomenon that affects visual covert orienting in a variety of experimental conditions.

Notwithstanding its apparently ubiquitous nature, suggestions have been made that IOR is not a unitary phenomenon. Specifically, Rafal et al. (1989) have suggested that IOR may actually reflect the operation of two underlying processes, one related to and the other independent of eye movements. More recent research has supported the suggestion that visual IOR is more complex than would appear at first glance. For example, Tipper et al. (1991) demonstrated that IOR can become associated with an object and may, in fact, move in accordance with its trajectory to a new location, apparently indicating the existence of separate "what" and "where" inhibitory mechanisms (see also Tipper et al., 1994). Rafal, Egly, and Rhodes (1994) proposed that these two components might operate independently; location-based IOR might act to create a motor bias against returning the eyes to a previously attended location, while objectbased IOR might act to reduce sensitivity to the object with which it is associated.

In contrast to the many studies of visual IOR, there has been little investigation of the possibility that there may be an inhibitory component to covert orienting of auditory attention. This apparent lack of interest may be un- 
derstandable given that there has been some controversy as to whether it is even possible to allocate auditory attention on the basis of spatial location or other features (e.g., Buchtel \& Butter, 1988). However, recent evidence has established quite clearly that auditory attention may be deployed in response not only to a location cue (Mondor \& Bryden, 1992a, 1992b; Mondor \& Zatorre, 1995; Spence \& Driver, 1994) but also to a frequency cue (Hafter, Schlauch, \& Tang, 1993; Mondor \& Bregman, 1994; Mondor, Zatorre, \& Terrio, in press; Scharf, Quigley, Aoki, Peachey, \& Reeves, 1987; Schlauch \& Hafter, 1991).

This evidence of the important role of auditory selective attention in sound perception, together with the multiplicity of mechanisms and features that have been proposed to control visual IOR, certainly raises the possibility that IOR may also characterize auditory covert orienting. Some evidence of this possibility has been reported recently by Reuter-Lorenz, Jha, and Rosenquist (1996), who examined response time (RT) to detect a noise-burst target as a function of the similarity of its location to that of a visual spatial cue. Their results suggested an inhibitory effect because subjects responded more quickly when cue and target differed in location than when they were identical. Although an intriguing result, the work of Reuter-Lorenz et al. leaves two issues unresolved. First, it is somewhat uncertain as to what extent the inhibitory effect reflects the operation of an auditory attention system. This uncertainty is suggested by recent studies of cross-modal covert orienting, which have shown that visual spatial cues have a remarkably small effect on auditory target judgments (Mondor \& Amirault, in press; Spence \& Driver, 1997). This marked difference in the magnitude of within- and between-modality cuing effects led Mondor and Amirault to argue that auditory and visual covert orienting systems were at least partially separate. If this suggestion is accurate, then, because ReuterLorenz et al. employed only a visual spatial cue, it is possible that their results reflect some type of interaction between auditory and visual systems rather than the unmodified operation of the auditory covert orienting system. Second, while IOR is normally defined functionally by the transition from a facilitative effect at short SOAs to an inhibitory effect at longer SOAs, Reuter-Lorenz et al. did not identify such a pattern, confining their investigation to lengthy SOAs of $1 \mathrm{sec}$ or more. With the study reported below, we set out to determine whether any evidence of an inhibitory component to covert orienting might be obtained when both cue and target were acoustic.

\section{The Present Study}

The experimental procedure was designed so as to be as similar as possible to that used in examinations of visual IOR. The time period between the onset of a cue and a subsequent target sound was varied randomly from 150 to $750 \mathrm{msec}$. In different conditions, the cue and the tar- get differed only either in location or in frequency. This manipulation was included both because sound identification might be facilitated by either spatial (Mondor \& Zatorre, 1995) or frequency (e.g., Mondor \& Bregman, 1994) cues and because Mondor et al. (in press) have shown that while location plays a dominant role in guiding visual selection (see, e.g., Tsal \& Lavie, 1988, 1993), location and frequency appear to be codominant in guiding auditory selection. Given this previous evidence, as well as the evidence that visual IOR may occur on the basis of variation in features other than location (e.g., Tipper et al., 1991), it would appear reasonable to expect that if there is an inhibitory component to auditory covert orienting, then it should be apparent whether cue and target differ in frequency or location. Finally, we attempted to maximize the probability of identifying any cuing effects that might occur in the location condition by using noise bursts, because such spectrally complex stimuli are more accurately localized than are pure tones (e.g., Moore, 1989). Pure tones were used in the frequency condition to simplify the frequency judgment required in the discrimination task. This difference in the spectral characteristics of cue and target in the location and frequency conditions allows for a preliminary investigation of the extent to which facilitative and inhibitory cuing effects might depend on the spectral nature of the stimuli.

Different groups of subjects were required to perform either a target-detection task in which simple RT was measured, or a target-discrimination task (localization or frequency identification) in which choice RT was measured. This manipulation was undertaken to examine the degree to which evidence of facilitative and inhibitory cuing effects might rely on specific task requirements. An expectation of observing cuing effects for an auditory detection task might appear to be rather optimistic. However, although the results of studies that have examined the effect of a location cue on target-detection performance have been rather mixed (cue-validity effects have been reported by Bedard, Massioui, Pillon, \& Nandrino, 1993, Mazzuchi, Cattelani, \& Umiltà, 1983, and Simon, 1967 , but not by Buchtel \& Butter, 1988, Posner, 1978, or Spence \& Driver, 1994), studies of frequency selectivity have quite reliably shown an effect of frequency cues on the accuracy of target detection (Greenberg \& Larkin, 1968; Dai, Scharf, \& Buus, 1991; Johnson \& Hafter, 1980; Macmillan \& Schwartz, 1975; Penner, 1972; Scharf et al., 1987; Schlauch \& Hafter, 1991; Sorkin, Pastore, \& Gilliom, 1968). In addition, Mondor et al. (in press) have shown that RT to detect a target tone embedded within a sequence of distractor tones is affected by target-distractor similarity in both frequency and location. This previous research would appear, then, to admit at least the possibility of observing an effect of frequency and location cues on target detection. To anticipate somewhat, such effects were, in fact, observed. 


\section{METHOD}

\section{Subjects}

Forty-eight undergraduate students attending Mount Allison University were paid for their participation. Twenty-four subjects performed a target-detection task, and the other 24 subjects performed a target-discrimination task. None of the subjects reported any corrected or uncorrected hearing problems.

\section{Materials}

Computer and Sound System. A 486/50 desktop workstation running the MAPLE software system (Bregman, Achim, \& Ahad, 1992) was used to present stimuli and collect responses. Sounds were presented through $5-\mathrm{cm}^{2}$ speakers located $15^{\circ}$ to the right and $15^{\circ}$ to the left of the listener. Each speaker occupied $2^{\circ}$ vertically and $2^{\circ}$ horizontally.

Sounds. Two pure tones, one of $555 \mathrm{~Hz}$ and the other of $869 \mathrm{~Hz}$ (these frequencies were chosen arbitrarily with the constraint that they not be harmonically related), and a single wideband $(0-10000 \mathrm{~Hz})$ noise burst were synthesized at a sampling rate of $16000 \mathrm{~Hz}$, using the MITSYN time-signal processing software package (Henke, 1990). All sounds were $100 \mathrm{msec}$ in duration and began and ended with 5-msec linear onset/offset amplitude ramps to eliminate onset and offset clicks. The sounds were presented to listeners at a comfortable intensity of approximately $65 \mathrm{~dB}$.

\section{Design and Procedure}

Listeners participated in two separate conditions. In the location condition, two identical noise bursts were presented in succession. These noise bursts could sound either from the same location (a "repeat" trial) or from different locations (a "change" trial). Noise bursts were used in the location condition in order to maximize the probability of identifying an effect of the cue-target relation (noise bursts are typically more accurately localized than are pure tonesMoore, 1989). In the frequency condition, two pure tones were presented in succession. These pure tones always sounded from the same location (either $15^{\circ}$ left or $15^{\circ}$ right, counterbalanced across listeners) but could be either of the same frequency (a "repeat" trial) or of different frequencies (a "change" trial). There was no predictive relation between the first (i.e., the cue) and second (i.e., the target) sounds in either the location or the frequency condition. The target was presented 150,450 , or $750 \mathrm{msec}$ following the onset of the cue. SOA was randomly selected on each trial. Subjects initiated each trial by pressing any key on a computer keyboard, with the subsequent trial beginning $750 \mathrm{msec}$ following this initiating keypress.
Different groups of subjects were required to make either targetdetection or target-discrimination responses. When target detection was required, (1) subjects responded by pressing any key on a computer keyboard, (2) no target was presented on $10 \%$ of trials, and listeners were to withhold a response on these catch trials, and (3) each subject completed 40 practice and 160 experimental trials (including 16 catch trials) for both the location and frequency conditions ( 400 trials total). When target discrimination was required, (1) listeners localized the target in the location condition and identified the pitch of the target in the frequency condition, (2) subjects responded by pressing either the " 1 " or the " 0 " key on a computer keyboard, (3) for both location and frequency conditions, the mapping of a particular key to a particular response was counterbalanced across listeners, and (4) subjects completed 36 practice and 144 experimental trials for each condition ( 360 trials total; catch trials were not included because of the extremely low probability of anticipatory responses when target identification is required). For each task, 12 subjects performed the frequency condition first and the other 12 subjects performed the location condition first. Analysis of RTs was based on correct responses only. In addition, RTs more than 2.5 SDs beyond the mean for each condition were excluded.

\section{RESULTS}

Mean RT, standard errors for the RT data, and percent errors for all conditions in the experiment are shown in Table 1. For simplicity, the results of the detection and discrimination tasks are presented separately, followed by a comparison of performance for the two tasks. In all three analyses, all simple effects were evaluated using a probability level of .05 . Therefore, in the description of the results, no specific mention is made of the significance level for any individual simple effect.

\section{Detection Task}

A three-way within-subjects analysis of variance (ANOVA) (condition [location, frequency] $\times$ SOA [150, $450,750 \mathrm{msec}$ ] $\times$ repetition [repeat, change]) was performed with RTs as the dependent variable. The main effect of SOA was significant $[F(2,46)=19.93, p<.001]$, while that of repetition approached significance $[F(1,23)$ $=3.54, p=.07]$. In general, listeners responded more quickly at 450 -msec SOA and on change trials. The

Table 1

Response Times (RT), Standard Errors for RT Data, and Percent Errors as a Function of Task, Condition, Repetition, and SOA

\begin{tabular}{|c|c|c|c|c|c|c|c|c|c|c|}
\hline & & \multicolumn{9}{|c|}{ Stimulus Onset Asynchrony } \\
\hline \multirow{2}{*}{\multicolumn{2}{|c|}{ Condition }} & & $150 \mathrm{~m}$ & & & $450 \mathrm{~m}$ & & & $750 \mathrm{~m}$ & \\
\hline & & RT & $S E$ & $\%$ Errors & RT & $S E$ & $\%$ Errors & $\mathrm{RT}$ & $S E$ & $\%$ Errors \\
\hline \multicolumn{11}{|c|}{ Detection Task } \\
\hline \multirow[t]{2}{*}{ Location } & Repeat & 428 & 16.95 & 0.17 & 423 & 13.75 & 1.56 & 453 & 15.89 & 2.43 \\
\hline & Change & 445 & 16.53 & 0.35 & 411 & 16.64 & 0.35 & 427 & 16.53 & 0.69 \\
\hline \multirow[t]{2}{*}{ Frequency } & Repeat & 415 & 16.99 & 0.17 & 409 & 14.94 & 1.22 & 458 & 19.28 & 1.04 \\
\hline & Change & 426 & 18.47 & 0.17 & 407 & 17.71 & 0.52 & 437 & 19.51 & 1.74 \\
\hline \multicolumn{11}{|c|}{ Discrimination Task } \\
\hline \multirow[t]{2}{*}{ Location } & Repeat & 469 & 26.40 & 0.42 & 452 & 21.77 & 0.83 & 465 & 21.66 & 1.67 \\
\hline & Change & 595 & 45.03 & 3.75 & 487 & 25.93 & 1.04 & 430 & 22.33 & 0.83 \\
\hline \multirow[t]{2}{*}{ Frequency } & Repeat & 521 & 28.96 & 4.58 & 499 & 25.34 & 2.92 & 500 & 26.64 & 3.54 \\
\hline & Change & 664 & 45.14 & 8.13 & 530 & 32.69 & 1.25 & 464 & 26.83 & 3.33 \\
\hline
\end{tabular}


interaction between condition and SOA was also significant $[F(2,46)=11.05, p<.001]$. For both conditions, RT was faster at $450-\mathrm{msec}$ SOA than at either 150 - or $750-\mathrm{msec}$ SOA. In addition, RT at $750-\mathrm{msec}$ SOA was significantly elevated relative to that at $150-\mathrm{msec}$ SOA for the frequency condition but not for the location condition.

Most importantly, the interaction shown in Table 1 between SOA and repetition also reached significance $[F(2,46)=21.59, p<.001]$. Further analysis revealed that a significant advantage for repeat trials at $150-\mathrm{msec}$ SOA reversed to a significant advantage for change trials at 750-msec SOA. In addition, the effect of SOA was significant for both repeat $[F(2,46)=27.08, p<.001]$ and change $[F(2,46)=13.07, p<.001]$ trials. While RT on repeat trials was significantly elevated at $750-\mathrm{msec}$ SOA relative to that at both $150-$ and $450-$ msec SOAs, RT on change trials was significantly reduced at 450 msec SOA relative to that at both $150-$ and $750-\mathrm{msec}$ SOAs. Planned comparisons revealed significant facilitative effects (repeat faster) at 150-msec SOA and significant inhibitory effects (change faster) at 750 -msec SOA for both the location and frequency conditions. The apparent advantage for change trials at $450-\mathrm{msec}$ SOA attained statistical significance for the location condition but not for the frequency condition. None of the other effects approached significance.

Analysis of error rates for the detection task was not warranted as few subjects made even one anticipatory response or false alarm (a response on a catch trial). False-alarm rates were $0.29 \%$ in the location condition and $0.32 \%$ in the frequency condition.

\section{Discrimination Task}

A three-way within-subjects ANOVA (condition $\times$ SOA $\times$ repetition) of the RT data revealed significant main effects of condition $[F(1,23)=11.16, p<.01]$, SOA $[F(2,46)=30.53, p<.001]$, and repetition $[F(1,23)=16.56, p<.001]$. Listeners localized tones more quickly than they identified frequencies and tended to respond more quickly at longer SOAs and on repeat trials. The only other effect to attain significance was the interaction between SOA and repetition $[F(2,46)=$ $23.41, p<.001]$. As shown in Table 1, listeners responded significantly more quickly on repeat trials at $150-$ and $450-\mathrm{msec}$ SOAs and on change trials at $750-$ msec SOA. In addition, while performance was relatively stable across SOAs for repeat trials $[F(2,46)=$ $1.92, p=.16]$, it did change significantly as a function of SOA for change trials $[F(2,46)=31.68, p<.001]$, with a significant reduction in RT at $450-\mathrm{msec}$ SOA relative to $150-\mathrm{msec}$ SOA and at $750-\mathrm{msec}$ SOA relative to 450-msec SOA. Planned comparisons revealed a significant facilitative effect (repeat trials faster) for both the location and the frequency conditions at $150-\mathrm{msec}$ SOA, as well as a significant inhibitory effect (change faster) for both conditions at $750-\mathrm{msec}$ SOA. An advantage for repeat trials at $450-\mathrm{msec}$ SOA was significant for the lo- cation condition but not for the frequency condition. No other effect approached significance.

A complementary analysis of the error data revealed significant main effects of condition $[F(1,23)=11.20$, $p<.01], \operatorname{SOA}[F(2,46)=7.39, p<.01]$, and repetition $[F(1,23)=4.46, p<.05]$. Listeners tended to respond more accurately in the location condition, at 450 -msec SOA, and on repeat trials. The interaction between condition and SOA also attained statistical significance $[F(2,46)=3.36, p<.05]$. In the frequency condition, performance varied as a function of SOA $[F(2,46)=$ $8.19, p<.01]$, with a significant reduction in error rate at $450-$ and $750-\mathrm{msec}$ SOAs relative to that at $150-\mathrm{msec}$ SOA. Performance in the location condition did not vary as a function of SOA $[F(2,46)=1.31, p=.28]$. Finally, a significant SOA $\times$ repetition interaction $[F(2,46)=$ $9.16, p<.001]$ resulted because of a significant difference in error rate for repeat and change trials only at 150 msec SOA, where a facilitative effect was apparent. None of the other effects approached significance.

\section{Comparison of Performance on Detection and Discrimination Tasks}

A four-way mixed ANOVA (task [detection, discrimination] $\times$ condition [location, frequency] $\times$ SOA [150, $450,750 \mathrm{msec}$ ] $\times$ repetition [repeat, change]) was performed with RTs as the dependent variable. This analysis revealed significant main effects of task $[F(1,46)=$ $6.52, p<.05]$, condition $[F(1,46)=6.39, p<.05]$, SOA $[F(2,92)=25.02, p<.001]$, and repetition $[F(1,46)=$ $11.69, p<.001]$. In general, listeners responded more slowly on the discrimination task, when frequency was the feature that was varied, at $150-\mathrm{msec}$ SOA and on change trials. In addition, two-way interactions between task and condition $[F(1,46)=10.35, p<.001]$, task and SOA $[F(2,92)=33.33, p<.001]$, task and repetition $[F(1,46)=19.57, p<.001]$, and SOA and repetition $[F(2,92)=33.24, p<.001]$ also reached significance.

These significant main effects and interactions were involved in two three-way interactions, one between task, condition, and SOA $[F(2,92)=5.51, p<.01]$ and the other between task, SOA, and repetition $[F(2,92)=$ $13.39, p<.001]$. The task $\times$ condition $\times$ SOA interaction attained significance because, as described in detail above, the condition $\times$ SOA interaction was significant for the detection task but not for the discrimination task.

The task $\times$ SOA $\times$ repetition interaction resulted because of significant differences between tasks in the nature of the SOA $\times$ repetition interaction. Although, a transition from facilitation at $150-\mathrm{msec}$ SOA to inhibition at $750-\mathrm{msec}$ SOA was apparent for both detection and discrimination tasks, performance did differ between the two tasks. Specifically, at $150-\mathrm{msec}$ SOA the facilitative effect was significantly larger for the discrimination task, while at 450-msec SOA the difference between the inhibitory effect for the detection task and the facilitative effect for the discrimination task was also significant. Tasks did not differ significantly in the mag- 
nitude of the inhibitory effect at $750-\mathrm{msec}$ SOA. More specific planned comparisons indicated that while a significant difference between tasks in the magnitude of the facilitative effect at $150 \mathrm{msec}$ was apparent for both location and frequency conditions, the reversal from inhibition (detection task) to facilitation (discrimination task) at $450-\mathrm{msec}$ SOA was significant for the location condition but not for the frequency condition. None of the other effects approached significance.

Because of the very low error rate for the detection task, error rates for the two tasks were not compared directly.

\section{DISCUSSION}

For both detection and discrimination tasks, and irrespective of whether cue-target location or frequency similarity was varied, an RT advantage in making target judgments for repeat trials at $150 \mathrm{msec}$ was reversed to an advantage for change trials at $750-\mathrm{msec}$ SOA. Although listeners were not explicitly required to shift attention away from a cued location or frequency prior to target presentation, this transition from facilitation at brief SOAs to inhibition at more lengthy SOAs has normally been taken as prima facie evidence of IOR in vision (e.g., Pratt \& Abrams, 1995). Indeed, an inhibitory effect at long SOAs alone has been interpreted as evidence of IOR (e.g., Reuter-Lorenz et al., 1996; Terry, Valdes, \& Neill, 1994). It would appear reasonable, then, to interpret the obtained pattern of performance as indicative of an active inhibition of returning auditory attention to a previously attended location or frequency (e.g., Houghton \& Tipper, 1994; Rafal \& Henik, 1994). This evidence of both location-based and frequency-based auditory IOR is consistent with the suggestion made by Mondor et al. (in press) that auditory selection is normally dependent on both location and frequency information. Although some evidence of a location-based inhibitory effect has recently been reported (e.g., Reuter-Lorenz et al., 1996; Schmidt, 1996), to our knowledge the present study provides the first demonstration of frequency-based IOR. Such a frequency-based effect, wherein location was held constant, suggests strongly that, under certain conditions, an inhibitory effect may be observed in the absence of oculomotor programming (this does not, of course, mean that planning and/or execution of eye movements does not contribute to location-based inhibitory effects).

That facilitative and inhibitory effects were apparent for both detection and discrimination tasks is consistent with studies of visual IOR (e.g., Kwak \& Egeth, 1992; Law et al., 1995). In addition, the significant effects obtained in the frequency conditions are quite consistent with previous investigations of the effect of frequency cues on both target identification (Mondor \& Bregman, 1994; Mondor et al., in press) and target detection (e.g., Greenberg \& Larkin, 1968; Mondor et al., in press; Wright \& Dai, 1994). However, evidence regarding effects of spatial cues on sound detection is somewhat equivocal. Of the previous investigations of this issue (Bedard et al.,
1993; Buchtel \& Butter, 1988; Mazzuchi et al., 1983; Posner, 1978; Simon, 1967; Spence \& Driver, 1994), only Spence and Driver's (1994) Experiment 8 was similar to the present study in that the effect of uninformative spatial cues on sound detection was examined. Because both automatic and voluntary processes may contribute to performance when informative cues are used (e.g., Müller \& Rabbitt, 1989), it is difficult to provide an explanation for the inconsistency in the results of such studies. In contrast, effects obtained using uninformative cues are thought to be a relatively pure indicator of the operation of automatic attentional processes. It is both for this reason as well as because of the procedural similarity of the two studies that we will confine our discussion to the apparent incompatibility of our results with those reported by Spence and Driver (1994). It is important to note, first, that this discrepancy may not be quite as irreconcilable as would appear at first glance. Indeed, the two sets of results are consistent in direction, with Spence and Driver reporting a nonsignificant $7-\mathrm{msec}$ facilitative effect at 100 -msec SOA and a nonsignificant 5 -msec inhibitory effect at 1,000-msec SOA. This difference of degree may be due to the fact that, in contrast to our study, in Spence and Driver's experiment, the cue and target differed spectrally.

Mondor (1995; Mondor et al., in press) has offered a theoretical interpretation of auditory cuing effects which may explain why spectral differences in the cue and target could reduce the magnitude of spatial cuing effects. Briefly, Mondor proposed an initial stage of perceptual integration in which acoustic information likely to have originated from the same source is grouped into auditory objects, or "streams" (see Bregman, 1990, for a comprehensive review of this process). Selection occurs during a subsequent stage in which streams are compared with an attentional template which holds an advance description of necessary target attributes. The speed of selection is determined by the degree of match between the template and the stream. Mondor further proposed that uninformative cues act to set the parameters of the attentional template in a bottom-up fashion. Given this model, then, the spectral mismatch between cue and target which occurred on every trial in Spence and Driver's (1994) experiment may have acted to reduce the selection speed advantage on valid trials, in essence reducing the magnitude of the cuing effects. In contrast, in our experiment, because cue and target could differ only in location, the selection speed advantage for valid trials would be preserved, thereby increasing the magnitude of the effect and its probability of being identified as significant.

The results of our study also document both a larger facilitative effect for the discrimination task and a change in the time course of the transition from facilitation to inhibition as a function of task requirements. One possibility is that, because both RTs and error rates were elevated in the discrimination task, both of these effects may be related, for whatever reason, to overall task difficulty. In contrast, the model described by Mondor et al. 
(in press) may account for the increased facilitative effect at 150-msec SOA for the discrimination task, if the specificity of the attentional template definition is increased when one of the primary features on which selection is based (location or frequency) is critical to performance of the task. According to this explanation, increasing the specificity of the template will act to increase the relative mismatch on change trials, thereby slowing selection and enhancing the performance difference between repeat and change trials. That the difference in the magnitude of the facilitative effect for the two tasks appeared to be primarily the result of a greatly elevated RT for change trials at $150-\mathrm{msec}$ SOA for the discrimination task is certainly consistent with this explanation. Such an account also raises one possible explanation of the extended duration of the facilitative effect in the discrimination task relative to the detection task. Specifically, if IOR results because of an active inhibition of processing information from previously attended locations or frequencies, then the time required for this inhibition to build up and overcome the initial facilitative effect may be lengthened as a result of increased specificity of the attentional template. Clearly, such explanations of the differences between tasks in the magnitude of the facilitative effect and the time course of the transition from facilitation to inhibition remain to be evaluated.

\section{REFERENCES}

Bedard, M. A., Massioui, F. E., Pillon, B., \& Nandrino, J. L. (1993). Time for reorienting of attention: A premotor hypothesis of the underlying mechanism. Neuropsychologia, 31, 241-249.

Bregman, A. S. (1990). Auditory scene analysis. London: MIT Press.

Bregman, A. S., Achim, A., \& Ahad, P. A. (1992). The MAPLE software system [Computer software]. McGill University, Department of Psychology.

Buchtel, H. A., \& ButTer, C. M. (1988). Spatial attentional shifts: Implications for the role of polysensory mechanisms. Neuropsychologia, 26, 499-509.

DaI, H., SCHARF, B., \& BUUS, S. (1991). Effective attenuation of signals in noise under focused attention. Journal of the Acoustical Society of America, 89, 2837-2842.

Grbson, B. S., \& EGETH, H. (1994a). Inhibition and disinhibition of return: Evidence from temporal order judgments. Perception \& Psychophysics, 56, 669-680.

Gibson, B. S., \& EGETH, H. (1994b). Inhibition of return to objectbased and environment-based locations. Perception \& Psychophysics, 56, 323-339.

GrEenBERG, G. Z., \& LARKIN, W. D. (1968). Frequency-response characteristic of auditory observers detecting signals of a single frequency in noise: The probe-signal method. Journal of the Acoustical Society of America, 44, 1513-1523.

Hafter, E. R., Schlauch, R. S., \& TANG, J. (1993). Attending to auditory filters that were not stimulated directly. Journal of the Acoustical Society of America, 94, 743-747.

HENKE, W. L. (1990). An interactive dialogue language for time signal processing [Computer software]. Cambridge, MA: MIT, Research Laboratory of Electronics.

Houghton, G., \& TipPer, S. P. (1994). A model of inhibitory mechanisms in selective attention. In D. Dagenbach \& T. H. Carr (Eds.), Inhibitory processes in attention, memory, and language (pp. 52-112). Toronto: Academic Press.

Huey, E. D., \& WeXLER, B. E. (1994). Abnormalities in rapid, auto- matic aspects of attention in schizophrenia: Blunted inhibition of return. Schizophrenia Research, 14, 57-63.

JoHnson, D. M., \& HAFTER, E. R. (1980). Uncertain-frequency detection: Cuing and condition of observation. Perception \& Psychophysics, 28, 143-149.

KWAK, H., \& EGETH, H. (1992). Consequences of allocating attention to locations and to other attributes. Perception \& Psychophysics, 57, 455-464.

LaW, M. B., PratT, J., \& Abrams, R. A. (1995). Color-based inhibition of return. Perception \& Psychophysics, 57, 402-408.

MaCmillan, N. A., \& SchWarTZ, M. (1975). A probe-signal investigation of uncertain-frequency detection. Journal of the Acoustical Society of America, 58, 1051-1058.

MAYLOR, A. M., \& HoCKEY, R. (1985). Inhibitory component of externally controlled covert orienting in space. Journal of Experimental Psychology: Human Perception \& Performance, 11, 777-787.

Mazzuchi, A., Cattelani, R., \& Umiltà, C. (1983). Hemispheric prevalence in acoustical attention. Brain \& Cognition, 2, 1-11.

Mondor, T. A. (1995, June). Allocating auditory attention to locations and frequencies. Paper presented at the annual meeting of the Canadian Society for Brain, Behaviour, and Cognitive Science, Halifax, NS.

Mondor, T. A., \& Amirault, K. J. (in press). Effect of same- and different-modality spatial cues on auditory and visual target identification. Journal of Experimental Psychology: Human Perception \& Performance.

Mondor, T. A., \& Bregman, A. S. (1994). Allocating attention to frequency regions. Perception \& Psychophysics, 56, 268-276.

Mondor, T. A., \& BRYDEN, M. P. (1992a). Auditory perceptual asymmetries: A function of the distribution of auditory attention. Perception \& Psychophysics, 52, 393-402.

MondoR, T. A., \& BRYDEN, M. P. (1992b). Orienting of auditory spatial attention: Effects of a lateralized tone cue. Neuropsychologia, 30 , 743-752.

Mondor, T. A., \& ZATORRE, R. J. (1995). Shifting and focusing auditory spatial attention. Journal of Experimental Psychology: Human Perception \& Performance, 21, 387-409.

Mondor, T. A., Zatorre, R. J., \& Terrio, N. A. (in press). Constraints on the selection of auditory information. Journal of Experimental Psychology: Human Perception \& Performance.

MOORE, B. C. J. (1989). An introduction to the psychology of hearing (3rd ed.). Toronto: Academic Press.

Müller, H. J., \& Rabbitr, P. M. A. (1989). Reflexive and voluntary orienting of visual attention: Time course of activation and resistance to interruption. Journal of Experimental Psychology: Human Perception \& Performance, 15, 315-330.

PENNer, M. J. (1972). The effect of payoffs and cue tones on detection of sinusoids of uncertain frequency. Perception \& Psychophysics, 11, 198-202.

Posner, M. I. (1978). Chronometric explorations of mind. Hillsdale, NJ: Erlbaum.

PosNer, M. I., \& COHEN, Y. (1984). Components of visual orienting. In H. Bouma \& D. G. Bowhuis (Eds.), Attention and performance $X$ (pp. 531-555). Hillsdale, NJ: Erlbaum.

PratT, J. (1995). Inhibition of return in a discrimination task. Psychonomic Bulletin \& Review, 2, 117-120.

PratT, J., \& Abrams, R. A. (1995). Inhibition of return to successively cued spatial locations. Journal of Experimental Psychology: Human Perception \& Performance, 21, 1343-1353.

Rafal, R. D., Calabresi, P. A., Brennan, C. W., \& Sciolto, T. K. (1989). Saccade preparation inhibits reorienting to recently attended locations. Journal of Experimental Psychology: Human Perception \& Performance, 15, 673-685.

RAFAL, R. D., EgLY, R., \& RHODES, D. (1994). Effects of inhibition of return on voluntary and visually guided saccades. Canadian Journal of Experimental Psychology, 48, 284-300.

RAFAL, R., \& HENIK, A. (1994). The neurology of inhibition: Integrating controlled and automatic processes. In D. Dagenbach \& T. H. Carr (Eds.), Inhibitory processes in attention, memory, and language (pp. 1-51). Toronto: Academic Press. 
Reuter-Lorenz, P. A., JhA, A. P., \& Rosenquist, J. N. (1996). What is inhibited in inhibition of return? Journal of Experimental Psychology: Human Perception \& Performance, 22, 367-378.

Scharf, B., Quigley, S., Aoki, C., Peachey, N., \& Reeves, A. (1987). Focused auditory attention and frequency sensitivity. Perception \& Psychophysics, 42, 215-223.

SChlaUch, R. S., \& HAFTER, E. R. (1991). Listening bandwidths and frequency uncertainty in pure-tone signal detection. Journal of the Acoustical Society of America, 90, 1332-1339.

SCHмIDT, W. C. (1996). Inhibition of return without visual input. Neuropsychologia, 34, 943-952.

SIMON, J. R. (1967). Ear preference in a simple reaction time task. Journal of Experimental Psychology, 75, 49-55.

Sorkin, R. D., Pastore, R. E., \& Gilliom, J. D. (1968). Signal probability and the listening band. Perception \& Psychophysics, 4, 10-12.

SPENCE, C. J., \& DRIVER, J. (1994). Covert spatial orienting in audition: Exogenous and endogenous mechanisms. Journal of Experimental Psychology: Human Perception \& Performance, 20, 555-574.

SPENCE, C. J., \& DrIVER, J. (1997). Audiovisual links in exogenous covert spatial orienting. Perception \& Psychophysics, 59, 1-22.

Terry, K. M., Valdes, L. A., \& NeIll, W. T. (1994). Does "inhibition of return" occur in discrimination tasks? Perception \& Psychophysics, 55, 279-286.

TipPer, S. P., Driver, J., \& Weaver, B. (1991). Object-centered inhibition of return of visual attention. Quarterly Journal of Experimental Psychology, 43A, 289-298.

TipPer, S. P., Weaver, B., Jerreat, L. M., \& Burak, A. L. (1994). Object-based and environment-based inhibition of return of visual attention. Journal of Experimental Psychology: Human Perception \& Performance, 20, 478-499.

Tsal, Y., \& Lavie, N. (1988). Attending to color and shape: The special role of location in selective visual processing. Perception \& Psychophysics, 44, 15-21.

TSAL, Y., \& LAVIE, N. (1993). Location dominance in attending to color and shape. Journal of Experimental Psychology: Human Perception \& Performance, 19, 131-139.

WRIGHT, B. A., \& DAI, H. (1994). Detection of unexpected tones with short and long durations. Journal of the Acoustical Society of America, 95, 931-938.

(Manuscript received November 4, 1996; revision accepted for publication February 5, 1997.) 